\title{
NEW SPECIES OF THE GENERA DIPLOBODES AND MACHADOCEPHEUS (ACARI, ORIBATIDA, CARABODIDAE) FROM THAILAND, WITH REMARKS ON SOME RELATED GENERA
}

\author{
Sergey G. Ermilov and Alexander A. Khaustov \\ Tyumen State University, Lenina str. 25, 625000 Tyumen, Russia \\ E-mails: ermilovacari@yandex.ru,https://orcid.org/0000-0002-0913-131X \\ alkhaustov@mail.ru,https://orcid.org/0000-0002-0306-112X
}

Two new species of oribatid mites of the family Carabodidae are described from litter in Thailand. Diplobodes parakanekoi sp. $\mathbf{n}$. differs from Diplobodes kanekoi, D. africanus and D. aokii by fewer notogastral setae in the $c$-row, different number of notogastral tubercles, presence of a translamella, and the localization of dorsal notogastral setae. Machadocepheus pararachii sp. n. differs from Machadocepheus rachii by the positions of dorsal notogastral setae $c_{1}$, da and la. The generic status of the related genera Diplobodes, Machadocepheus, Gibbicepheus, Gibbibodes, Kalloia, Neocarabodes, Sagittabodes and Zimbabweae is discussed.

Key words: carabodid mites, systematics, morphology, Oriental region, Oribatida.

\section{INTRODUCTION}

At present, oribatid mites (Acari, Oribatida) of the family Carabodidae are poorly studied in Thailand, and only a few species have so far been recorded (Aокi 1965, Mahunka 2008, Fernandez et al. 2018, 2019) namely: Aokiella latiseta Mahunka, 2008; Archegocepheus imadatei Aoki, 1965; Congocepheus thailandae Fernandez, Theron, Leiva et Jordaan, 2018; Diplobodes kanekoi (Aoki, 1958), Diplobodes thailande Fernandez, Theron, Leiva et Jordaan, 2019, and Gibbicepheus frondosus (Aoki, 1959).

In the course of taxonomic survey of carabodid mites collected from Thailand during the Russian expedition in 2017 we found two new species belonging to the genera Diplobodes Aoki, 1958 and Machadocepheus Balogh, 1958. The genus Diplobodes was proposed by Аокі (1958) with Diplobodes kanekoi Aoki, 1958 as type species. According to Ermilov et al. (2013) and Fernandez et al. (2019) it comprises seven species, which are distributed in the Oriental and Ethiopian regions, and Japan. The genus Machadocepheus was proposed by BALOGH (1958) with Machadocepheus excavatus Balogh, 1958 as type species. According to the catalogue of Subías (2019), it comprises 10 species, which are distributed in the Ethiopian region, New Guinea, Sri Lanka, and Mexico.

The main goal of our present paper is to describe and illustrate two new species Diplobodes parakanekoi sp. n. and Machadocepheus pararachii sp. n. and discuss some morphological and taxonomic similarities and differences be- 
tween Diplobodes, Machadocepheus and some related taxa, e.g., Gibbicepheus Balogh, 1958, Gibbibodes Mahunka, 1986, Kalloia Mahunka, 1985, Neocarabodes Balogh et Mahunka, 1969(a), Sagittabodes J. et P. Balogh, 1992, and Zimbabweae Fernandez, Theron et Leiva, 2016.

\section{MATERIAL AND METHODS}

The oribatid mite material was collected during the Russian expedition to Thailand in 2017. Litter was collected by using a manual method. The mites were extracted into $75 \%$ ethanol using Berlese's funnels without electric lamps in laboratory conditions.

Specimens were mounted in lactic acid on temporary cavity slides for measurement and illustration of the new species. Body length was measured in lateral view, from the tip of the rostrum to the posterior edge of the notogaster. Notogastral width refers to the maximum width of notogaster in dorsal view. Lengths of body setae were measured in lateral aspect. All body measurements are presented in micrometer. Formulas for leg setation are given in parentheses according to the sequence trochanter-femur-genu-tibia-tarsus (famulus included). Formulas for leg solenidia are given in square brackets according to the sequence genu-tibia-tarsus.

Drawings were made with a camera lucida using a Leica transmission light microscope “Leica DM 2500". Images were obtained with an AxioCam ICc3 camera using a Carl Zeiss transmission light microscope "Axio Lab.A1".

The general morphological terminology used in this paper mostly follows that of F. Grandjean: see Travé and VACHON (1975) for references, Norton (1977) for leg setal nomenclature, and Norton and Behan-Pelletier (2009) for overview.

The following abbreviations are used: lam = lamella; tlam = translamella; $r$ = ridge; $d e p=$ depression; $t u=$ tutorium; $r o, l e, i n, b s=$ rostral, lamellar, interlamellar and bothridial setae, respectively; $b o=$ bothridium; $t=$ tooth; $h l s=$ hump-like structure (process); $t u b=$ tubercle; $c, d a, d m, d p, l a, l m, l p, h, p=$ notogastral setae; $c l d=$ circumlateral depression; $i m, i p$, $i h$, ips = notogastral lyrifissures; gla = opisthonotal gland opening; $a, m, h=$ subcapitular setae; $P d I, P d I I=$ pedotecta I and II, respectively; $1 a, 1 b, 1 c, 2 a, 3 a, 3 b, 3 c, 4 a, 4 b, 4 c=$ epimeral setae; dis = discidium; $g, a g, a n, a d=$ genital, aggenital, anal and adanal setae, respectively; $\mathrm{iad}=$ adanal lyrifissure; p.o. = preanal organ; $\mathrm{cvr}=$ circumventral ridge; $\mathrm{Tr}, \mathrm{Fe}, \mathrm{Ge}, \mathrm{Ti}, \mathrm{Ta}=$ leg trochanter, femur, genu, tibia and tarsus, respectively; p.a. = porose area; $\omega, \sigma, \phi=$ leg solenidia; $\varepsilon=$ leg famulus; $v, e v, b v, l, d, f t, t c, i t, p, u, a, s, p v=$ leg setae.

\section{SYSTEMATICS \\ Diplobodes parakanekoi sp. $\mathrm{n}$. (Figs 1A-C, 2A-D, 5A-C)}

Diagnosis. Body size 581-630 × 282-332. Notogaster foveolate. Translamella present. Rostral setae thick, spinose. Lamellar and interlamellar setae setiform, roughened. Bothridial setae with slightly developed lanceolate head, heavily barbed. Notogaster with 12 or 13 (one pair of setae $c$ present or absent) pairs of notogastral setae of medium size, setiform, roughened; $d a, d m$, $d p, l a, l m$ and $l p, h_{1}$ (together) located on the six pairs of large tubercles. Five 
pairs of notogastral setae $\left(p_{1}-p_{3^{\prime}} h_{2}\right.$ and $\left.h_{3}\right)$ in posterolateral position. Epimeral setation 3-1-3-3; $1 a, 1 c, 2 a$ and $3 a$ minute, $1 b, 3 b, 3 c, 4 a, 4 b$ and $4 b$ of medium size, setiform, roughened. Anogenital region with specific system of anogenital depressions. Anal setae short, spiniform, other anogenital setae of medium size, setiform, roughened.

Description. Measurements. Body length 630 (holotype: male), 581, 614 (two paratypes: males); notogaster width 332 (holotype), 282, 298 (two paratypes).

Integument (Figs 1A-C, 2A-D). Body color brown. Body covered by thick layer of gel-like cerotegument. Body surface (including subcapitular mentum and genae, genital and anal plates) microgranulate (diameter of tubercles less than 1). Notogaster, circummarginal region of ventral plate and antiaxial part of all leg femora and trochanters III, IV sparsely foveolate (diameter of foveoles up to 10). Projecting parts of lamellae foveate.

Prodorsum (Figs 1A-C). Rostrum broadly rounded. Lamellae long (slightly shorter than prodorsum), slightly divided mediodistally by transverse ridge into two parts, distally with triangular projection. Translamella broad. Tutoria long, strong, ridge-like, not reaching lateral margins of prodorsum. With depressions between lamellae, tutoria and pedotecta I (Fig. 1C). Region between lamellae slightly depressed. Interbothridial region with indistinct longitudinal wrinkles. Rostral setae (45-49) thick, with numerous spines. Lamellar and interlamellar setae similar in length (41-45), setiform, roughened; le located on lamellae, in located in interlamellar region. Bothridial setae (53-61) with slightly developed lanceolate head, heavily barbed, curved semiovally in mediodistal part. Bothridia interrupted ventrally, with small ventroposterior tooth. Exobothridial setae and their alveoli not observed.

Notogaster (Figs 1A, 1C, 5A, 5C). Narrow furrow between prodorsum and notogaster present. Anterior notogastral margin almost straight, posterior notogastral margin broadly rounded. Posterolateral part of notogaster with indistinct longitudinal wrinkles. Notogaster with six pairs of tubercles and 12 or 13 (one pair of setae $c$ present or absent) pairs of notogastral setae (36-45) setiform, roughened; of these, $d a, d m$, dp, la and $l m$ located on five pairs of separated tubercles, $l p$ and $h_{1}$ located on the sixth pair of tubercles, and setae $p_{1}-p_{3^{\prime}} h_{2}$ and $h_{3}$ in posterolateral position. Anterior part of notogaster with or without one pair of medial setae (c), humeral shoulders always without setae. Posterior notogastral and circumlateral depressions well developed. Lyrifissures ia not observed, other lyrifissures and opisthonotal gland openings well visible; im and gla close and lateral to lateral tubercles bearing setae $l a$, ip between $p_{1}$ and $p_{2^{\prime}}$ ips and ih on lateral sides of notogaster.

Gnathosoma (Figs 1B, 1C). Typical for Carabodidae (Ermilov \& Corpuz-Raros 2016, Ermilov \& Starý 2018, Ermilov et al. 2019). Subcapitulum longer than wide (139-147 × 94-102). Subcapitular setae ( $a 16 ; m 16 ; h$ 14) setiform, similar in thickness, roughened. Postpalpal setae (8) spiniform. Palps (77-82) with setation $0-2-1-3-9(+\omega)$. Solenidion of palptarsi long, bacilliform. Chelicerae (139-147) with two setiform, barbed setae, cha (41) longer than chb (16). Trägårdh's organ of chelicerae elongate triangular.

Epimeral and lateral podosomal regions (Figs 1B, 1C, 5B, 5C). Epimeral setation 3-13-3. Epimeral setae $1 a, 1 c, 2 a$ and $3 a$ minute (4), spiniform, $1 b, 3 b, 3 c, 4 a, 4 b$ and $4 b$ (32-36) setiform, roughened. Sternal region depressed. Pedotecta II rounded in ventral view. Discidia triangular, rounded distally. With one small depression behind acetabula IV and with one large elongate depression on lateral sides of body (between acetabula IV and notogastral margin). 
Anogenital region (Figs 1B, 1C, 5B). With specific system of anogenital depressions (Fig. 1B): one large depression between genital and anal apertures, partially divided longitudinal median border; one pair of depressions close and lateral to genital aperture; one pair of depressions bearing aggenital setae; one pair of depressions bearing adanal setae $a d_{3}$; one pair of depressions lateral to the former and latter depressions. Usually with slight-

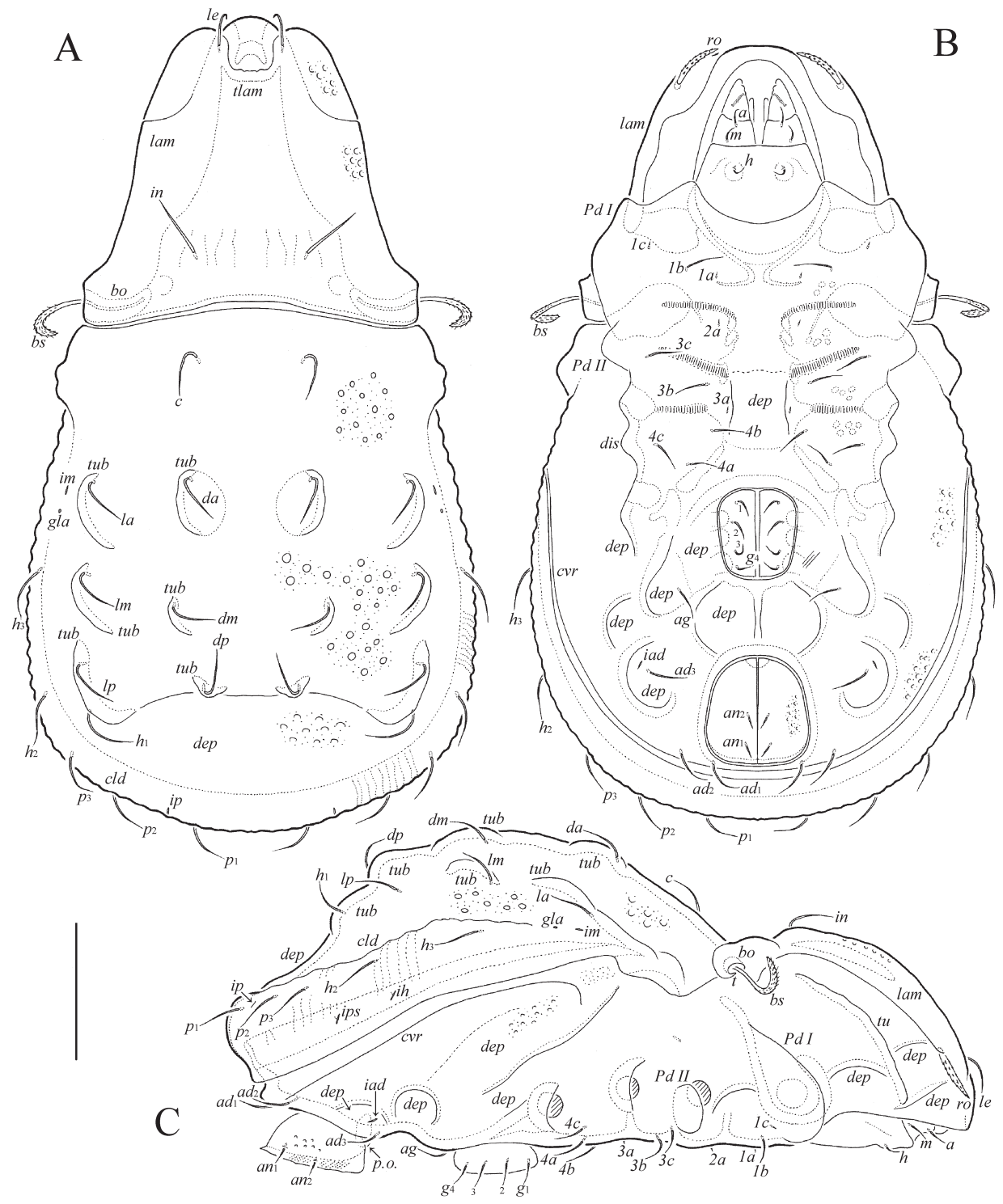

Fig. 1. Diplobodes parakanekoi sp. n., adult: $\mathrm{A}=$ dorsal view, $\mathrm{B}=$ ventral view (legs not shown), $\mathrm{C}=$ lateral view (legs not shown). Scale bar: $100 \mu \mathrm{m}$ 
ly visible, thin, diagonal furrows lateral to genital aperture. Four pairs of genital (20-28), one pair of aggenital (32-36) and three pairs of adanal (32-36) setae setiform, roughened. Two pairs of anal setae (12) spiniform. Adanal lyrifissures removed from anal aperture and located close to $a d_{3}$. Circumventral ridge visible.

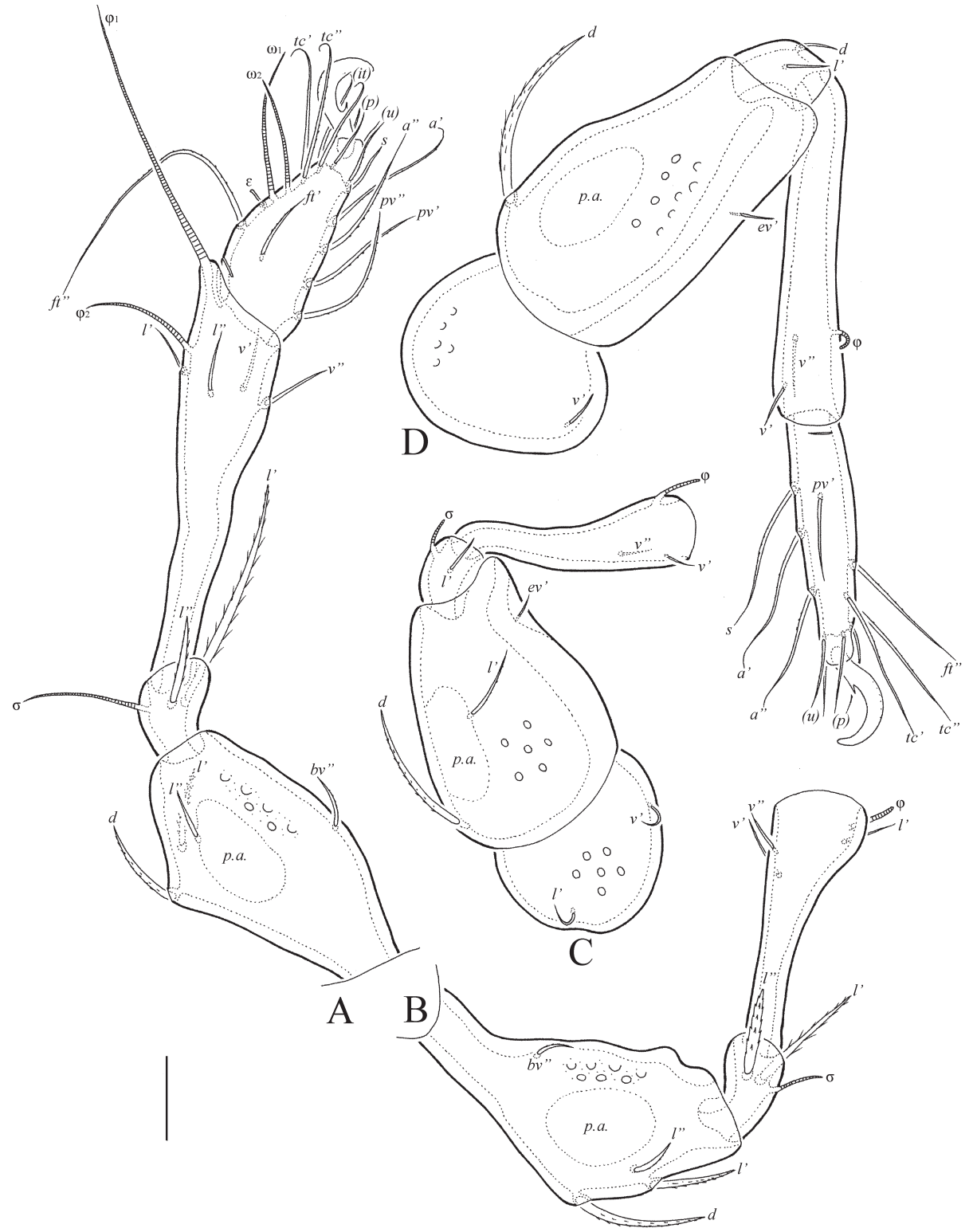

Fig. 2. Diplobodes parakanekoi sp. n., adult: $\mathrm{A}=$ leg $\mathrm{I}$, without trochanter, right, antiaxial view, B = leg II, without trochanter and tarsus, left, antiaxial view, C = leg III, without tarsus, left, antiaxial view, D = leg IV, left, antiaxial view. Scale bar: $20 \mu \mathrm{m}$ 
Legs (Figs 2A-D). Claw of each leg strong, sparsely barbed dorsally and with one tooth ventrobasally. Porose area on all femora visible; porose area on trochanters not observed. Formulas of leg setation and solenidia: I (1-4-2-4-16) [1-2-2], II (1-4-2-3-15) [1-1-2], III (2-3-1-2-15) [1-1-0], IV (1-2-2-2-11) [0-1-0]; homology of setae and solenidia indicated in Table 1. Famulus of tarsi I short, erect, blunt-ended, inserted posterior to solenidion $\omega_{1}$. Solenidion $\phi_{1}$ on tibiae I very long, setiform; $\omega_{1}$ and $\omega_{2}$ on tarsi I, $\phi_{2}$ on tibiae I and $\sigma$ on genua I, II of medium size, slightly thickened, blunt-ended; other solenidia short, bacilliform. Dorsoanterior apophysis of tibiae I (bearing $\phi_{1}$ ) developed.

Material examined. Holotype (male) and two paratypes (two males): southwest Thailand, Phuket Province, close to Karon Beach, $7^{\circ} 49^{\prime} 32.8^{\prime \prime} \mathrm{N} 98^{\circ} 17^{\prime} 46.5^{\prime \prime} \mathrm{E}$, litter in forest vegetation, 4.04.2017 (A. A. Khaustov).

Type deposition. The holotype is deposited in the collection of the Senckenberg Museum of Natural History, Görlitz, Germany. Two paratypes are deposited in the collection of the Tyumen State University Museum of Zoology, Tyumen, Russia. All in ethanol with a drop of glycerol.

Etymology. The species name parakanekoi refers to the similarity between the new species and Diplobodes kanekoi Aoki, 1958.

Remarks. Diplobodes parakanekoi sp. n. differs from the other representatives of the genus Diplobodes by one important morphological trait: notogaster with 12 or 13 pairs of setae (without or with one pair of setae $c$ ) versus 14 or 15 pairs (with two or three pairs of setae $c$ ). However, the general morphology of the new species corresponds well to the generic diagnosis of Diplobodes (ERMILOv et al. 2013) in other morphological traits therefore, we included this species into the genus Diplobodes.

Diplobodes parakanekoi sp. n. is morphologically most similar to Diplobodes kanekoi Aoki, 1958 from Japan and the Oriental region (see AoKi 1958, ErmiLov et al. 2013), D. africanus Mahunka, 1987 from Kenya (see MaHunkA 1987, FERnANdez et al. 2019) and D. aokii Mahunka, 1989 from Kenya (see MaHunkA 1989) in having several large notogastral tubercles bearing the notogastral se-

Table 1. Leg setation and solenidia of adult Diplobodes parakanekoi sp. n. and Machadocepheus pararachii sp. n.

\begin{tabular}{lccccc}
\hline Leg & Tr & $F e$ & $G e$ & $T i$ & $T a$ \\
\hline I & $v^{\prime}$ & $d,(l), b v^{\prime \prime}$ & $(l), v^{\prime *}, \sigma$ & $(l),(v), \phi_{1^{\prime}} \phi_{2}$ & $(f t),(t c),(i t),(p),(u),(a), s,(p v), \varepsilon, \omega_{1^{\prime}} \omega_{2}$ \\
II & $v^{\prime}$ & $d,(l), b v^{\prime \prime}$ & $(l), v^{\prime *}, \sigma$ & $l^{\prime},(v), \phi$ & $(f t),(t c),(i t),(p),(u),(a), s,(p v), \omega_{1^{\prime}} \omega_{2}$ \\
III & $l^{\prime}, v^{\prime}$ & $d, l^{\prime}, e v^{\prime}$ & $l^{\prime}, \sigma$ & $(v), \phi$ & $(f t),(t c),(i t),(p),(u),(a), s,(p v)$ \\
IV & $v^{\prime}$ & $d, e v^{\prime}$ & $d, l^{\prime}$ & $(v), \phi$ & $f t^{\prime \prime},(t c),(p),(u),(a), s, p v^{\prime}$ \\
\hline
\end{tabular}

Note: Roman letters refer to normal setae, Greek letters to solenidia (except $\varepsilon=$ famulus). Single prime (') marks setae on anterior and double prime (") setae on posterior side of the given leg segment. Parentheses refer to a pair of setae.

* = seta $v^{\prime}$ on genua I and II not observed in D. parakanekoi sp. n. (versus developed in M. pararachii sp. n.) 
tae and a foveolate notogaster. However, the new species differs from $D$. kanekoi by fewer notogastral setae of the $c$-row (one pair or without them versus two or three pairs), the absence of notogastral tubercles in position of setae $c$-row (versus one pair of tubercles present), setae $c$ (if developed) inserted on notogastral surface (versus setae $c_{1}$ inserted on tubercles) and the localization of notogastral setae $l a$ and $l m$ on separate tubercles (versus tubercles bearing $l a$ and $l m$ connected). The new species differs from $D$. africanus and $D$. aokii by fewer notogastral setae of the $c$-row (one pair or without them versus two pairs), the presence of a translamella (versus absent), and the localization of notogastral setae $l p$ and $h_{1}$ on one tubercle on either side (versus $l p$ and $h_{1}$ inserted on separate tubercles).

\section{Machadocepheus pararachii sp. n.}

(Figs 3A-C, 4A-D, 5D-F)

Diagnosis. Body size 481-564 × 282-332. Notogaster foveolate. Translamella present. Rostral setae spinose. Lamellar and interlamellar setae setiform, roughened. Bothridial setae with slightly developed lanceolate head, heavily barbed. Broad and deep depression in anterior half of notogaster and median notogastral hump-like process well developed. Notogaster with 15 pairs of notogastral setae short, setiform, roughened; of these, $c_{1^{\prime}} c_{2^{\prime}} d p$ and $l a$ located in anterior notogastral depression, $c_{3}$ located on humeral shoulders, $d m, l m, d p, l p, h_{1}$ and $h_{2}$ located on hump-like process, and setae $p_{1}-p_{3}$ and $h_{3}$ in posterolateral position. Epimeral setation 3-1-3-3; $1 a, 1 c, 2 a$ and $3 a$ minute, $1 b$, $3 b, 3 c, 4 a, 4 b$ and $4 c$ of medium size, setiform, roughened. Anogenital region with specific system of anogenital depressions. Anal setae short, spiniform, other anogenital setae of medium size, setiform, roughened.

Description. Measurements. Body length 481 (holotype: male), 514, 564 (two paratypes: male and female, respectively); notogaster width 282 (holotype), 298, 332 (two paratypes: male and female, respectively).

Integument (Figs 3A-C, 4A, C, D). Body color brown. Body covered by thick layer of gel-like cerotegument. Body surface (including subcapitular mentum and genae, genital and anal plates) microgranulate (diameter of tubercles less than 1). Prodorsum, notogaster, circummarginal region of ventral plate, subcapitulum and antiaxial part of all leg femora sparsely foveolate (diameter of foveoles up to 8). Projecting parts of lamellae foveate.

Prodorsum (Figs 3A-C). Rostrum broadly rounded. Lamellae long (slightly shorter than prodorsum), distally with triangular projection. Translamella broad. One pair of interlamellar hump-like processes well developed, connected anteriorly by thick, transverse ridge. Basal part of prodorsum with median depression. Tutoria long, strong, ridge-like, reaching lateral margins of prodorsum. With depressions between lamellae, tutoria and pedotecta I (Fig. 2C). Rostral setae (32-36) thick, with numerous spines. Lamellar and interlamellar setae similar in length (16), setiform, roughened; le located on lamellae, in located 
on hump-like processes. Bothridial setae (45-53) with slightly developed lanceolate head, heavily barbed, curved semiovally in mediodistal part. Bothridia slightly interrupted ventrally. Exobothridial setae and their alveoli not observed.

Notogaster (Figs 3A, 3C, 5D, 5F). Furrow between prodorsum and notogaster absent. Anterior notogastral margin almost straight, posterior notogastral margin broadly rounded. Broad and deep depression in anterior half of notogaster and median notogastral

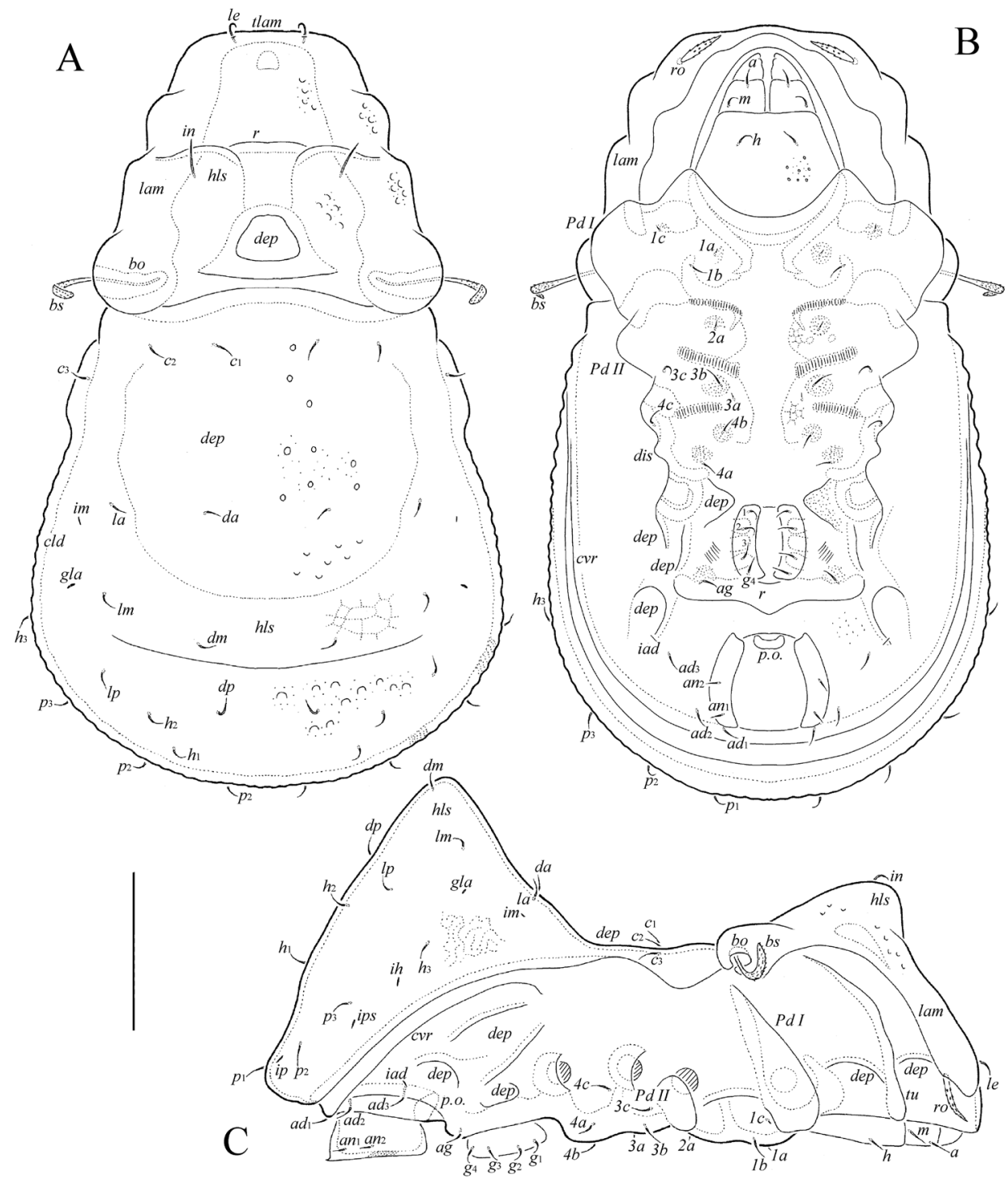

Fig. 3. Machadocepheus pararachii sp. n., adult: $\mathrm{A}=$ dorsal view, $\mathrm{B}=$ ventral view (legs not shown), $\mathrm{C}=$ lateral view (legs not shown). Scale bar: $100 \mu \mathrm{m}$ 


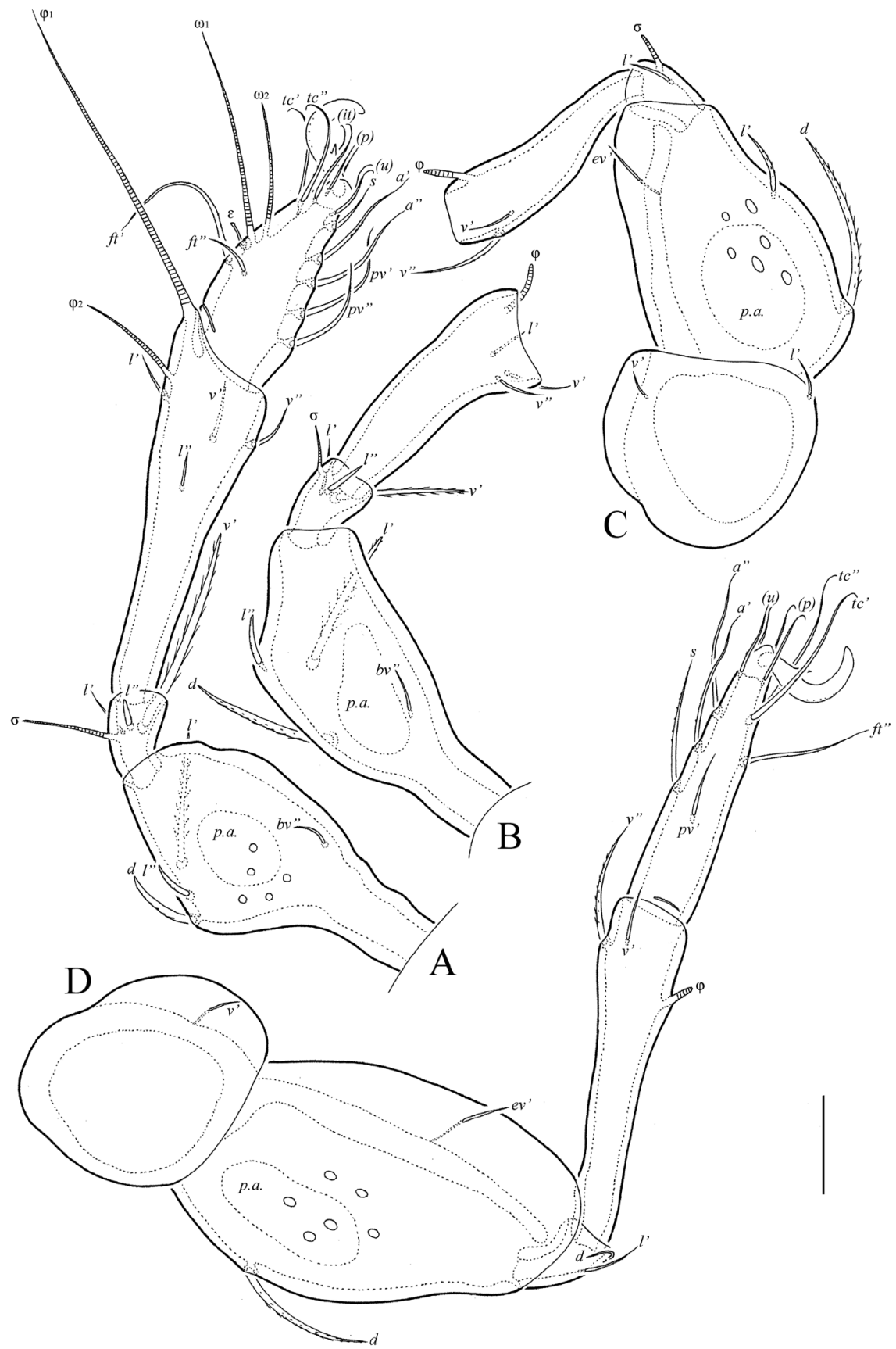

Fig. 4. Machadocepheus pararachii sp. n., adult: $\mathrm{A}=$ leg I, without trochanter, right, antiaxial view, B = leg II, without trochanter and tarsus, right, antiaxial view, C = leg III, without tarsus, right, antiaxial view, D = leg IV, right, antiaxial view. Scale bar: $20 \mu \mathrm{m}$ 
hump-like process well developed. Hump-like structure with slight, numerous longitudinal wrinkles, forming partially reticulate pattern. Notogaster with 15 pairs of notogastral setae (16) setiform, roughened; of these, $c_{1}, c_{2}$, $d p$ and la located in depression, $c_{3}$ located on humeral shoulders, $d m, l m, d p, l p, h_{1}$ and $h_{2}$ located on hump-like process, and setae $p_{1}-p_{3}$ and $h_{3}$ in posterolateral position. Circumlateral depressions slightly developed. Lyrifissures ia not observed, other lyrifissures and opisthonotal gland openings well visible; im located lateral to la, gla lateral to $l m$, ip between $p_{1}$ and $p_{2^{\prime}}$ ips and ih on lateral sides of notogaster.

Gnathosoma (Figs 3B, 3C). Typical for Carabodidae (Ermilov \& Corpuz-Raros 2016, Ermilov \& Starý 2018, Ermilov et al. 2019). Subcapitulum longer than wide (123-131 × 77-90). Subcapitular setae ( $12-14 ; m$ 12-14; $h$ 8-10) setiform, similar in thickness, rough-

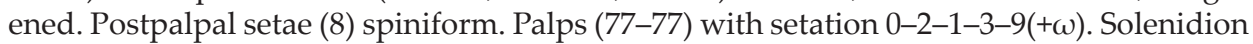
of palptarsi long, bacilliform. Chelicerae (123-131) with two setiform, barbed setae, cha (41) longer than chb (16). Trägårdh's organ of chelicerae elongate triangular.

Epimeral and lateral podosomal regions (Figs 3B, 3C, 5E, 5F). Epimeral setation 3-1-3-3. Epimeral setae 1a, 1c, $2 a$ and $3 a$ minute (4), spiniform, $1 b, 3 b, 3 c, 4 a, 4 b$ and $4 c$ (16) setiform, roughened, often located in round cluster of granules. Pedotecta II rounded in ventral view. Discidia triangular, rounded distally. With one small depression behind acetabula IV and with one large elongate depression on lateral sides (between genitoaggenital region and notogastral margin).

Anogenital region (Figs 3B, 3C, 5E). With specific system of anogenital depressions (Fig. 3B): one pair of depressions removed and lateral to genital aperture; one pair of depressions removed and lateral to aggenital region. Thick transverse ridge located posterior to genital aperture. Usually with slightly visible, thin, diagonal furrows lateral to genital
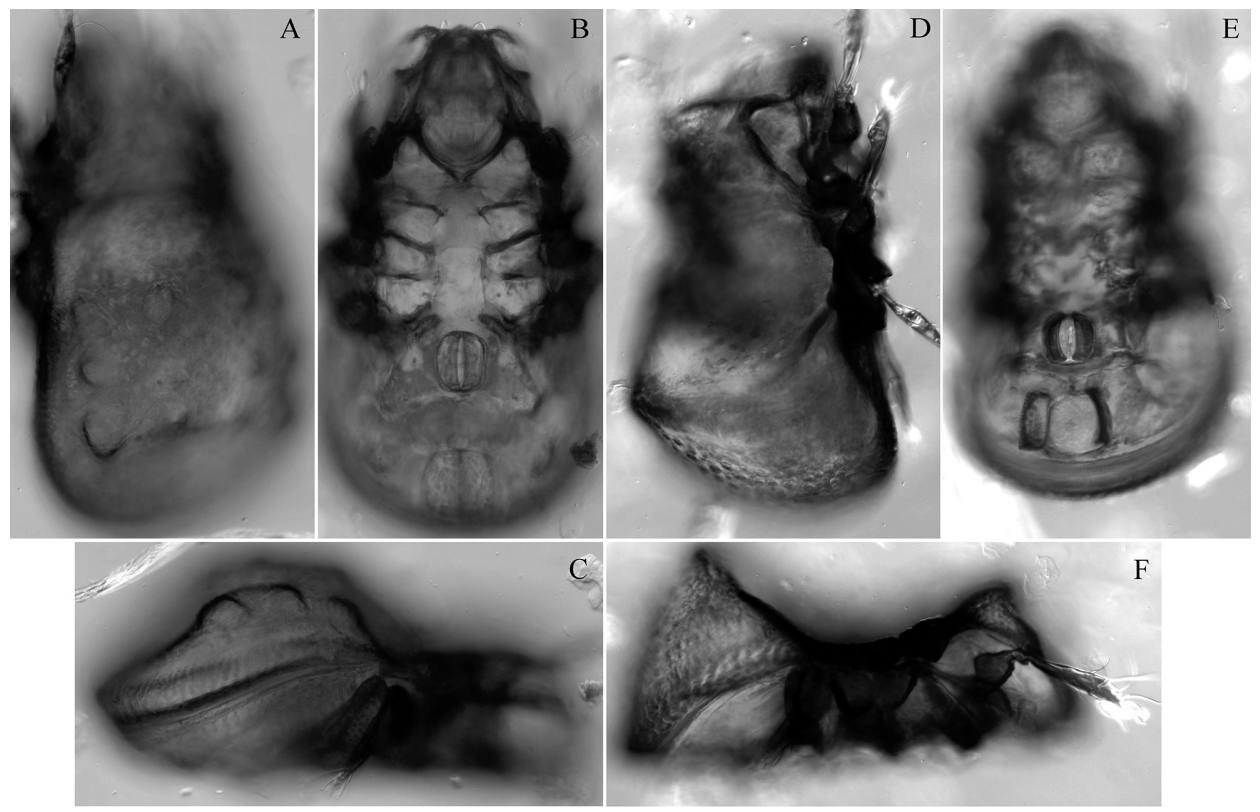

Fig. 5. Diplobodes parakanekoi sp. n. (A-C) and Machadocepheus pararachii sp. n. (D-F), adult, microscope images: $\mathrm{A}, \mathrm{D}=$ dorsolateral view; $\mathrm{B}, \mathrm{E}=$ ventral view; $\mathrm{C}, \mathrm{F}=$ lateral view 
aperture. Four pairs of genital (12), one pair of aggenital (16) and three pairs of adanal (16) setae setiform, roughened. Two pairs of anal setae (8) spiniform. Adanal lyrifissures removed from anal aperture and located close to $a d_{3}$. Circumventral ridge visible.

Legs (Figs 4A-D). Claw of each leg strong, sparsely barbed dorsally and with one tooth ventrobasally. Porose area on all femora visible; porose area on trochanters not observed. Formulas of leg setation and solenidia: I (1-4-3-4-16) [1-2-2], II (1-4-3-3-15) [1-1-2], III (2-3-1-2-15) [1-1-0], IV (1-2-2-2-11) [0-1-0]; homology of setae and solenidia indicated in Table 1. Famulus of tarsi I short, erect, blunt-ended, inserted posterior to solenidion $\omega_{1}$. Solenidion $\phi_{1}$ on tibiae I very long, setiform; $\omega_{1}$ and $\omega_{2}$ on tarsi I, $\phi_{2}$ on tibiae I and $\sigma$ on genua I, II of medium size, slightly thickened, blunt-ended; other solenidia short, bacilliform. Dorsoanterior apophysis of tibiae I (bearing $\phi_{1}$ ) developed.

Material examined. Holotype (male) and two paratypes (male and female): southwest Thailand, Phuket Province, close to Karon Beach, $7^{\circ} 49^{\prime} 32.8^{\prime \prime} \mathrm{N} 98^{\circ} 17^{\prime} 46.5^{\prime \prime} \mathrm{E}$, litter in forest vegetation, 4.04.2017 (A. A. Khaustov).

Type deposition. The holotype is deposited in the collection of the Senckenberg Museum of Natural History, Görlitz, Germany. Two paratypes are deposited in the collection of the Tyumen State University Museum of Zoology, Tyumen, Russia. All in ethanol with a drop of glycerol.

Etymology. The species name pararachii refers to the similarity between the new species and Machadocepheus rachii Fernandez, Theron, Rollard et Leiva, 2014.

Remarks. Machadocepheus pararachii sp. n. is morphologically most similar to Machadocepheus rachii Fernandez, Theron, Rollard et Leiva, 2014 from Gabon (see Fernandez et al. 2014) in having well developed prodorsal and notogastral hump-like structures, a deep, smooth notogastral depression, and the presence of 15 pairs of short notogastral setae. However, the new species differs from the latter by the localization of notogastral setae $c_{1}$, da and $l a$ in the notogastral depression (versus on the hump-like process).

\section{GENERAL REMARKS}

1. Diplobodes, Machadocepheus, Gibbicepheus, Kalloia. These genera are morphologically similar in many traits, therefore their taxonomic status is treated differently by different authors (see some opinions, synonymies and combinations in Aoki 1970, Mahunka 1986, J. \& P. Balogh 1992, Ermilov et al. 2013, 2019, Fernandez et al. 2016, 2019, Subías 2004, 2018, 2019).

According to recent studies of the family Carabodidae, the prodorsal and notogastral depressions and hump-like processes are basic morphological traits on generic level. Based on these traits, Diplobodes differs from the other related genera by the presence of a large posterior notogastral depression, the absence of a large anterior notogastral depression, and the presence of centrodorsal prodorsal and notogastral hump-like processes. Machadocepheus differs from the other related genera by the presence of a large anterior notogastral depression, centrodorsal prodorsal and notogastral hump-like processes and 
by the absence of (or slightly developed) large posterior notogastral depression. Gibbicepheus differs from the other related genera by the absence of large anterior and posterior notogastral depressions and centrodorsal prodorsal and notogastral hump-like processes. Kalloia differs from other related genera by the presence of large anterior and posterior notogastral depressions and a centrodorsal notogastral hump-like process, and by the absence of centrodorsal prodorsal hump-like processes.

However, several important morphological structures of some carabodid species were not described and drawn well in the original descriptions and detailed redescriptions are mostly absent therefore, interpretation and judgment on generic traits and status of the listed genera and systematic placement of their species are problematic. Perhaps, the basic morphological traits given above (presence or absence of prodorsal and notogastral depressions and hump-like processes), may not be the only differential traits, and other traits (e.g. morphology, number and localization notogastral setae or ventral depressions) might also be important for systematics of Diplobodes, Machadocepheus, Gibbicepheus and Kalloia as well. For example, we note a group of species in Gibbicepheus (e.g., G. baccanensis Jeleva et Vu, 1987, G. chinensis Wen, 1992, G. frondosus (Aoki, 1959), G. micheli Mahunka, 1978, G. novus Hammer, 1973, G. rugosus Mahunka, 1978, G. waterhousei Balogh et Mahunka, 1978) which have phylliform notogastral setae, of these, anterior setae located close to each other and removed from anterior notogastral margin, what distinguishes this group from the type species Gibbicepheus elevatus Balogh, 1958 and other Gibbicepheus species. Perhaps, this group may have an independent generic or subgeneric status.

Preliminarily we support the independence of Diplobodes, Machadocepheus, Gibbicepheus and Kalloia and reject any synonymies and lowering of generic rank however, additional studies (especially phylogenetic or molecular) are necessary to clarify the status of each.

2. Neocarabodes and Gibbibodes. The monotypic genus Neocarabodes was proposed by BALOGH and MahunKa (1969a) with Neocarabodes sexpilosus Balogh et Mahunka, 1969 as type species. The monotypic genus Gibbibodes was proposed by MaHunKa (1986) with Gibbibodes similis Mahunka, 1986 as type species. Neocarabodes sexpilosus and G. similis (see also Maнunka 1986) have posterior notogastral depression (generic traits of Diplobodes) and correspond to other morphological traits of Diplobodes, except in having six and five pairs of genital setae, respectively. Therefore we consider these taxa as subgenera of Diplobodes.

Furthermore, the number of genital setae is an important subgeneric trait in Carabodidae: four pairs are the standard number of genital setae. Species with similar morphology, but with more than four pairs of genital setae are 
grouped in one separate subgenus (e.g., Austrocarabodes (Uluguroides) Mahunka, 1983 (five to nine pairs); Carabodes (Phyllocarabodes) Balogh et Mahunka, 1969(b) (five to six pairs); Yoshiobodes (Dongnaibodes) Ermilov, Shtanchaeva, Subías et Anichkin, 2014 (five to six pairs); see Ermilov et al. 2014; Subías 2019). Neocarabodes and Gibbibodes have more than four pairs of genital setae and it is of little importance how many more pairs, be it either six or five. Hence, it would be logical to consider Gibbibodes as a subjective junior synonym of the subgenus Diplobodes (Neocarabodes).

3. Sagittabodes, Zimbabweae. The genus Sagittabodes was proposed by J. and P. BAlOGH (2002) with Machadocepheus sagitta Balogh et Mahunka, 1966 as type species. The genus Zimbabweae was proposed by Fernandez et al. (2016) with Zimbabweae pluosiae Fernandez, Theron et Leiva, 2016 as type species. All morphological traits of these genera and their type species are very similar, therefore Subías (2018) fairly synonymized Zimbabweae (we completely support this opinion), and included Sagittabodes as subgenus in Machadocepheus.

The genus Sagittabodes differs from Machadocepheus by the presence of a median longitudinal ridge in the anterior notogastral depression. However, some other species form different carabodid genera having similar structure (e.g., Camcarabodes korupensis Ermilov et Starý, 2018, Gibbicepheus sisiri Sanyal, 1990, Kalloia gerdweigmanni Ermilov, Sandmann et Scheu, 2019, Machadocepheus filiferus Mahunka, 1986, Machadocepheus leoneae Fernandez, Theron, Rollard et Leiva, 2014, Machadocepheus tuberculosus Mahunka, 1987), therefore we believe that this trait is most likely a species trait (not generic/subgeneric). Hence, it would be more logical to consider Sagittabodes as a subjective junior synonym of the genus Machadocepheus.

Acknowledgements - We cordially thank two anonymous reviewers for the valuable comments.

\section{REFERENCES}

AокI, J. (1958): Eine neue Gattung von Carabodidae aus der Insel Hachijo, Japan. - Zoological Magazine 67: 390-392.

Аокı, J. (1959): Die Moosmilben (Oribatei) aus Südjapan. - Bulletin of the Biogeographical Society of Japan 21: 1-22.

AокI, J. (1965): Oribatiden (Acarina) Thailands. I. - Nature and Life in Southeast Asia 4: 129-193.

AокI, J. (1970): The oribatid mites of the Islands of Tsushima. - Bulletin of the National Science Museum, Tokyo 13: 395-442.

BAlogh, J. (1958): Oribatides nouvelles de l'Afrique tropicale. - Revue de Zoologie et de Botanique Africaines 58: 1-34. 
Balogh, J. \& Balogh, P. (1992): The oribatid mite genera of the World. Vol. 1. - Hungarian Natural History Museum, Budapest, 263 pp.

BALOGH, J. \& BALOGH, P. (2002): Identification keys to the oribatid mites of the Extra-Holarctic regions. Vol. 1. - Well-Press Publishing Limited, Miskolc, 453 pp.

Balogh, J. \& Mahunka, S. (1966): New oribatids (Acari) from South Africa. - Acta Zoologica Academiae Scientiarum Hungaricae 12: 1-23.

Balogh, J. \& Mahunka, S. (1969a): The scientific results of the Hungarian soil zoological expeditions to South America. 10. Acari: Oribatids, collected by the second expedition. I. - Acta Zoologica Academiae Scientiarum Hungaricae 15: 1-21.

Balogh, J. \& Mahunka, S. (1969b): The zoological results of the Hungarian soil zoological expeditions to South America. 11. Acari: oribatids from the material of the second expedition, II. - Opuscula Zoologica, Budapest 9: 31-69.

Balogh, J. \& Mahunka, S. (1978): Data to the oribatid fauna of Australia (Acari), I - Opuscula Zoologica, Budapest 15: 31-49.

Ermilov, S. G. \& Corpuz-Raros, L. A. (2016): Contribution to the knowledge of carabodid oribatid mites (Acari, Oribatida, Carabodidae) of the Philippines. - Systematic and Applied Acarology 21: 1055-1068. https://doi.org/10.11158/saa.21.8.6

Ermilov, S. G. \& Starý, J. (2018): Camcarabodes korupensis gen. nov., sp. nov. (Acari, Oribatida, Carabodidae) from Cameroon. - Systematic and Applied Acarology 23: 532-538. https://doi.org/10.11158/saa.23.3.11

Ermilov, S. G., Aoki, J. \& Anichkin, A. E. (2013): Description of Chistyakovella insolita gen. nov., sp. nov., and redescription of the type species of Diplobodes, D. kanekoi Aoki, 1958 (Acari: Oribatida: Carabodidae). - Zootaxa 3608: 178-190. https://doi. org/10.11646/zootaxa.3608.3.2

Ermilov, S. G., Sandmann, D. \& Scheu, S. (2019): Contribution to the knowledge of the oribatid mite genus Kalloia (Acari, Oribatida, Carabodidae), with description of a new species from Indonesia. - Acarologia: 59: 323-334. https://doi.org/10.24349/acarologia/20194334

Ermilov, S. G., Shtanchaeva, U. Ya., Subías, L. S. \& Anichkin, A. E. (2014): A new subgenus and three new species of oribatid mites of the genus Yoshiobodes (Acari, Oribatida, Carabodidae) from Vietnam. - Zootaxa 3795: 401-420. https://doi.org/10.11646/ zootaxa.3795.4.1

Fernandez, N., Theron, P., Rollard, C. \& Leiva, S. (2014): The family Carabodidae (Acari, Oribatida) VIII. The genus Machadocepheus (first part) Machadocepheus leoneae sp. n. and Machadocepheus rachii sp. n. from Gabon. - ZooKeys 456: 1-28. https://doi. org/10.3897/zookeys.456.8570

Fernandez, N., Theron, P. \& Leiva, S. (2016): Revision of the family Carabodidae (Acari: Oribatida) XI. Congocepheus kardiae sp. nov. and Zimbabweae pluosiae gen. nov., sp. nov. from the Republic of Zimbabwe. - International Journal of Acarology 42: 341357. https://doi.org/10.1080/01647954.2016.1199138

Fernandez, N., Theron, P., Leiva, S. \& JordaAn, A. (2018): Revision of the family Carabodidae (Acari: Oribatida) XVI. Synkrotima tsalakpmenoi sp. nov. from Zimbabwe and Kenya, and Congocepheus thailandae sp. nov. from Thailand, including a complementary study of Cavaecarabodes hauseri (Mahunka 1989). - Zootaxa 4504: 371-389. https://doi.org/10.11646/zootaxa.4504.3.4

Fernandez, N., Theron, P., Leiva, S. \& JordaAn, A. (2019): Revision of the family Carabodidae (Acari: Oribatida) XVII. Redescription of Diplobodes africanus Mahunka, 1987 from Kenia. Description of Diplobodes thailande sp. nov. from Thailand and 
Rwandabodes kayoveae gen. nov., sp. nov. from Rwanda. - Zootaxa 4619: 401-430. https://doi.org/10.11646/zootaxa.4619.3.1

Hammer, M. (1973): Oribatids from Tongatapu and Eua, the Tonga Islands, and from Upolu, Western Samoa. - Det Kongelige Danske Videnskabernes Selskab Biologiske Skrifter 20: $1-70$.

Jeleva, M. \& VŨ, M. Q. (1987): New oribatids (Oribatei, Acari) from the northern part of Vietnam. - Acta Zoologica Bulgarica 33: 10-18.

MahunKA, S. (1978): Neue und interessante Milben aus dem Genfer Museum XXVII. A first survey of the oribatid (Acari) fauna of Mauritius, Reunion and the Seychelles I. - Revue suisse de Zoologie 85: 177-236.

Mahunka, S. (1983): Oribatids from the Eastern Part of the Ethiopian Region II. - Acta Zoologica Academiae Scientiarum Hungaricae 29: 151-180.

MahunKa, S. (1985): Mites (Acari) from St. Lucia (Antilles). 2. Oribatida. - Acta Zoologica Academiae Scientiarum Hungaricae 31: 119-178.

MahunKa, S. (1986): A survey of the family Carabodidae C. L. Koch, 1836 (Acari: Oribatida). - Acta Zoologica Academiae Scientiarum Hungaricae 32: 73-135.

Mahunka, S. (1987): A survey of the family Carabodidae C. L. Koch, 1836 (Acari: Oribatida). II. - Acta Zoologica Academiae Scientiarum Hungaricae 33: 399-434.

Manunka, S. (1989): Oribatids from the southern Hemisphere (Acari: Oribatida). - Acta Zoologica Academiae Scientiarum Hungaricae 35: 41-79.

MahunKa, S. (2008): More oribatids from Thailand (Acari: Oribatida). - Revue suisse de Zoologie 115: 623-649.

Norton, R. A. (1977): A review of F. Grandjean's system of leg chaetotaxy in the Oribatei (Acari) and its application to the family Damaeidae. Pp. 33-61. In: Dindal, D. L. (ed.): Biology of oribatid mites. - SUNY College of Environmental Science and Forestry, Syracuse.

Norton, R. A. \& Behan-Pelletier, V. M. (2009): Suborder Oribatida. Chapter 15. Pp. 430564. In: Krantz, G. W. \& Walter, D. E. (eds): A manual of acarology. - Texas Tech University Press, Lubbock.

SAnyal, A. K. (1990): On a collection of Oribatei (Acari: Cryptostigmata) from Silent Valley, Kerala (India) with descriptions of six new species. - Records of the Zoological Survey of India 86: 467-483.

Subías, L. S. (2004): Listado sistemático, sinonímico y biogeográfico de los ácaros oribátidos (Acariformes, Oribatida) del mundo (1758-2002). - Graellsia 60: 3-305. https://doi. org/10.3989/graellsia.2004.v60.iExtra.218

Subías, L. S. (2018): Listado sistemático, sinonímico y biogeográfico de los ácaros oribátidos (Acariformes: Oribatida) del mundo (excepto fósiles). [Online version accessed in January 2018], 605 pp.

SubíAs, L. S. (2019): Listado sistemático, sinonímico y biogeográfico de los ácaros oribátidos (Acariformes: Oribatida) del mundo (excepto fósiles). [Online version accessed in March 2019], 536 pp.

Travé, J. \& VAChon, M. (1975): François Grandjean. 1882-1975 (Notice biographique et bibliographique). - Acarologia 17: 1-19.

WEN, Z. (1992): Description of new and unrecorded soil oribatid mites from China (Acari: Oribatida). - Acta Arachnologica Sinica 1: 31-38.

Received July 17, 2019, accepted September 22, 2019, published March 6, 2020 
